\title{
Internal sphincter and the nature of haemorrhoids
}

\author{
B. D. HANCOCK \\ From Wythenshawe Hospital, Manchester
}

SUMMARY Internal anal sphincter activity has been studied in 84 patients with haemorrhoids and 40 asymptomatic subjects. Activity was estimated by measuring maximum resting anal pressure with a water filled anal balloon probe $7 \mathrm{~mm}$ in diameter connected to a strain gauge pressure transducer. There was greater activity of the internal sphincter in patients with haemorrhoids than in controls, but there was no significant relationship between sphincter activity and duration of symptoms, predominant symptom (bleeding or prolapse), severity of symptoms, history of pain, history of straining at stool, or size of haemorrhoids. Straining at stool occurred significantly more often in patients whose main complaint was prolapse than in those whose main complaint was bleeding. Anal dilatation reduced sphincter activity and the best clinical results were obtained in those with the most active sphincter. An internal sphincter abnormality may be an aetiological factor in some patients but there must be other factors as well. Straining at stool may determine whether bleeding or prolapse is the predominant symptom.

The internal sphincter is overactive in some patients with haemorrhoids (Kerremans, 1969; Hancock and Smith, 1975). This is in evidence by an increased resting anal pressure and the presence of ultra slow pressure waves $(0 \cdot 6-1 \cdot 9 / \mathrm{min})$. This activity when present is abolished by anal dilatation (Hancock and Smith, 1975) with relief of symptoms, so it seems possible that a sphincter abnormality is related to the development of symptoms in patients with haemorrhoids.

The clinical picture produced by haemorrhoids is very variable, and, in order to investigate this possible relationship, an attempt was made to correlate internal sphincter function with symptoms and appearances in series of patients with haemorrhoids.

\section{Methods}

Anal pressure and motility were measured with an anal probe consisting of a small balloon built into a hollow Perspex rod of $7 \mathrm{~mm}$ diameter (Fig. 1). The balloon was filled with water and inflated to produce a slight convexity of its surface and was connected via fine polyethylene tubing to a Statham strain gauge pressure transducer. This in turn was connected to a Devices multichannel recording machine and the tracings were produced on heat sensitive paper.

Received for publication 20 December 1976
The recording was taken without bowel preparation and before any examination. The recording was taken with the probe at centimetre steps from the anal verge and lasted about 15 minutes and the average pressure at each position in the anal canal was estimated with reference to a calibration of 100 $\mathrm{cm} \mathrm{H}_{2} \mathrm{O}$ (Fig. 2). The resting pressure was often steady (Fig. 3), but sometimes regular pressure waves of long frequency and high amplitude were seen. If these pressure waves had a frequency of less than $2 /$ min and an amplitude greater than $25 \mathrm{~cm} \mathrm{H}_{2} \mathrm{O}$ they were called ultra slow waves (Fig. 3). It has been shown previously that ultra slow waves persist under anaesthesia with the external sphincter paralysed and are associated with the highest anal pressure (Hancock and Smith, 1975). This suggests that both are caused by activity of the internal anal sphincter. In this study maximum anal pressure has been used as the single measurement of internal sphincter activity for purposes of comparison.

Eighty-four patients with haemorrhoids were studied before treatment. They all had a detailed history, examination, and an anal pressure recording. In addition, 40 patients in hospital who had no past or present anorectal symptoms were studied as controls.

The mean age of the controls was 47.9 $\pm 15 \cdot 2$ SD years, and of the patients with haemorrhoids was $47 \cdot 4 \pm 13 \cdot 1 \mathrm{SD}$ years. 


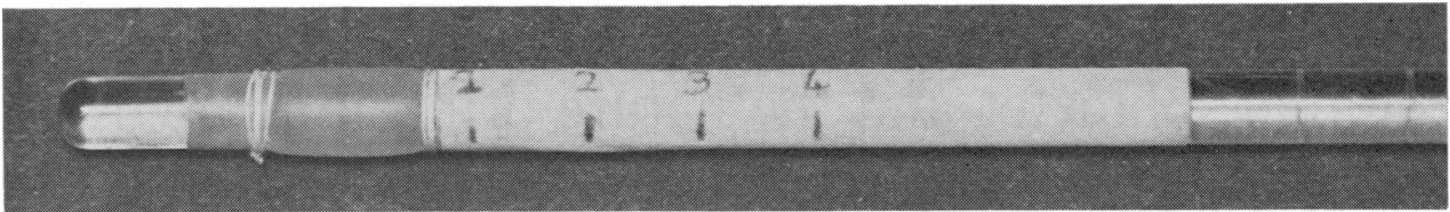

Fig. 1 The anal probe. Marked in centimetre steps from the mid point of the water filled balloon.

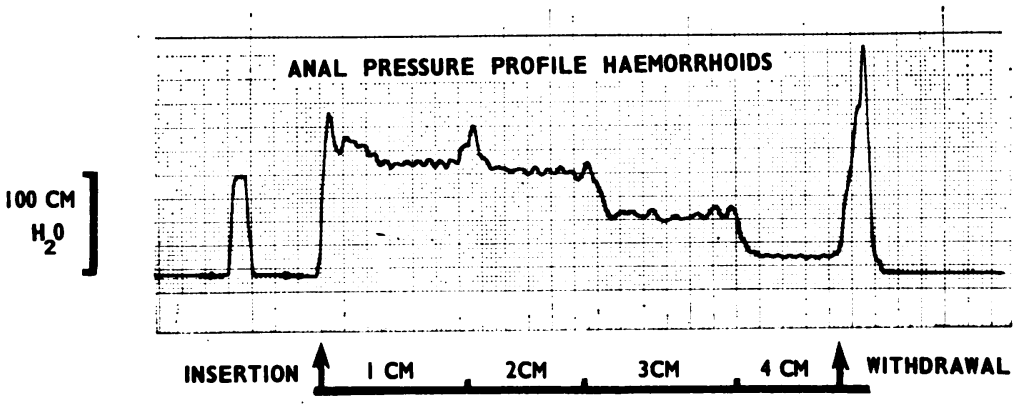

MINUTES

Fig. 2 Short anal pressure profile from a patient with haemorrhoids.

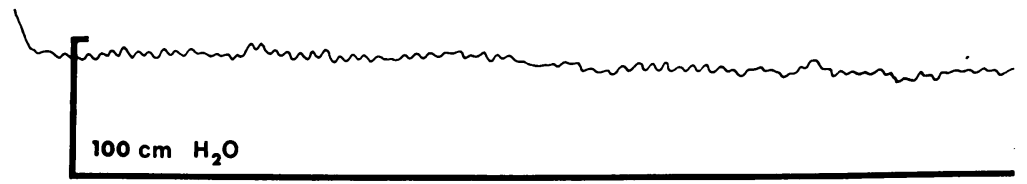

\section{Respiration}

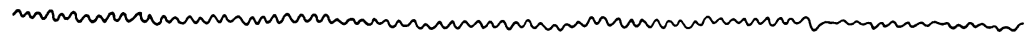

Time in minutes

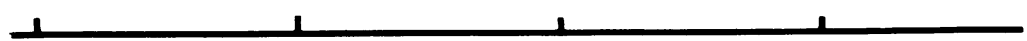

Fig. 3 (a) Flat tracing with slow waves from a normal subject.

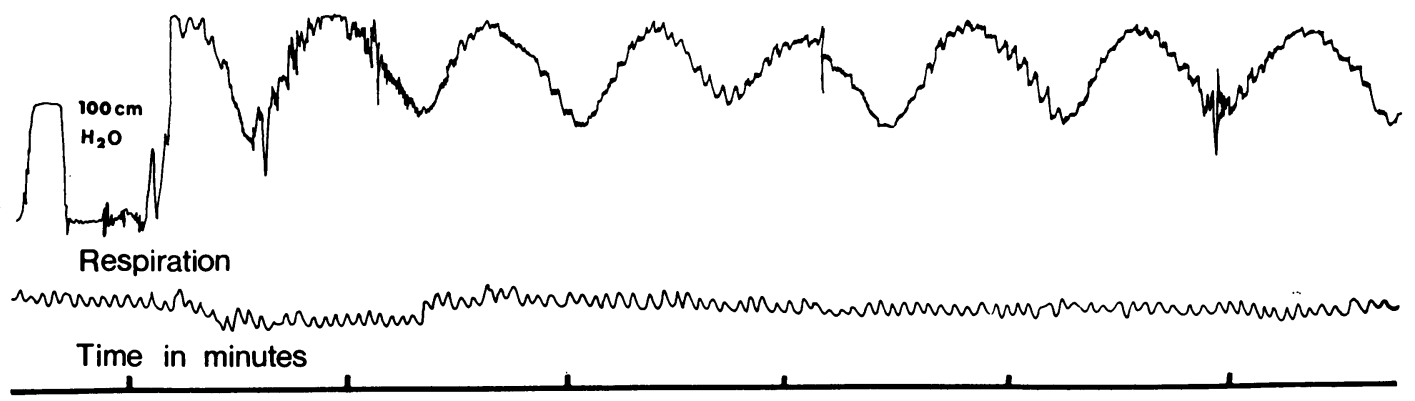

Fig. 3 (b) Sustained ultra slow waves from a patient with haemorrhoids. 


\section{Results}

\section{MAXIMUM ANAL PRESSURE}

The mean anal pressure of the 84 patients with haemorrhoids $\left(107 \pm 23.0 \mathrm{SD} \mathrm{cm} \mathrm{H}_{2} \mathrm{O}\right)$ was much greater than that of the 40 controls $(85.0 \pm 20.5 \mathrm{SD}$ $\mathrm{cm} \mathrm{H}_{2} \mathrm{O}$ ). This difference was highly significant $(z=5.42, \mathrm{P}<0.001)$.

\section{ULTRA SLOW WAVES}

Ultra slow waves, either sustained or fading, were present at the position of maximum anal pressure in two of the 40 controls $(5 \%)$ and in 35 of 84 patients with haemorrhoids $(42 \%)$. This difference was highly significant $\left(\chi^{2}=20 \cdot 7, \mathrm{P}<0.0005\right)$.

\section{FACTORS RELATED TO ANAL PRESSURE IN} NORMAL SUBJECTS AND PATIENTS WITH HAEMORRHOIDS

Age

There was a trend towards lower anal pressure with increasing age in the 40 normal subjects, but this was not significant $(r=0.25, P>0.05)$. In the 84 patients with haemorrhoids this trend was present to a greater degree and was significant $(r=0.29$, $P<0.01)$.

\section{Presence of asymptomatic haemorrhoids}

Twelve of the 40 controls had some evidence of haemorrhoids on proctoscopy. The mean maximum resting anal pressure in those with haemorrhoids $\left(85.0 \pm 20.7 \mathrm{SD} \mathrm{cm} \mathrm{H}_{2} \mathrm{O}\right)$ was no different from those without $\left(85.9 \pm 20.8 \mathrm{SD} \mathrm{cm} \mathrm{H} \mathrm{H}_{2} \mathrm{O}\right)$.

\section{DEGREE OF HAEMORRHOIDS}

There was no significant difference between patients who had haemorrhoids of differing degrees (Table 1).

\section{DURATION OF SYMPTOMS}

There was no significant correlation between length of history and maximum resting anal pressure $(r=0 \cdot 15, P=0 \cdot 12)$.

\section{PREDOMINANT SYMPTOM}

Patients were grouped according to their predominant symptoms as follows. There was no significant difference between the groups (Table 2):

\section{SEVERITY OF SYMPTOMS AT TIME OF}

\section{RECORDING}

The mean maximum resting anal pressure of those in remission (mild or no symptoms $103.9 \pm 24 \cdot 1 \mathrm{SD} \mathrm{cm}$ $\mathrm{H}_{2} \mathrm{O}$ ) was similar to those with an exacerbation (moderate or severe symptoms 109.2 $\pm 20.9 \mathrm{SD} \mathrm{cm}$ $\mathrm{H}_{2} \mathrm{O}, \mathrm{P}=0.4$ ).
Table 1 Degree of haemorrhoids

\begin{tabular}{|c|c|c|c|}
\hline Degree & $\begin{array}{l}\text { Mean max. RAP } \\
\mathrm{Cm} \mathrm{H}_{3} \mathrm{O}\end{array}$ & $S D$ & $n$ \\
\hline $\begin{array}{l}\text { First (bleeding only) } \\
\text { Second (prolapse with spontaneous }\end{array}$ & $104 \cdot 1$ & $25 \cdot 8$ & 18 \\
\hline $\begin{array}{l}\text { reduction) } \\
\text { Third A (prolapse requiring } \\
\text { replacement but only at bowel }\end{array}$ & $108 \cdot 3$ & $23 \cdot 2$ & 16 \\
\hline $\begin{array}{l}\text { action) } \\
\text { Third B (prolapse at times other than }\end{array}$ & 112.4 & $23 \cdot 8$ & 23 \\
\hline $\begin{array}{l}\text { bowel action) } \\
\text { Third C (permanent prolapse) }\end{array}$ & $\begin{array}{l}106 \cdot 9 \\
107 \cdot 2\end{array}$ & $\begin{array}{l}17 \cdot 5 \\
24 \cdot 0\end{array}$ & $\begin{array}{r}22 \\
5\end{array}$ \\
\hline
\end{tabular}

Table 2 Predominant symptom

\begin{tabular}{llll}
\hline & $\begin{array}{l}\text { Mean max. RAP } \\
\text { cm } H, O\end{array}$ & $S D$ & $n$ \\
\hline Bleeding only & $108 \cdot 0$ & $25 \cdot 8$ & 18 \\
Bleeding worse than prolapse & $109 \cdot 5$ & $25 \cdot 5$ & 13 \\
Bleeding and prolapse equally & & & \\
$\quad$ troublesome & $110 \cdot 0$ & $18 \cdot 7$ & 24 \\
Prolapse worse than bleeding & $101 \cdot 8$ & $23 \cdot 4$ & 19 \\
Prolapse only & $108 \cdot 2$ & $19 \cdot 6$ & 10 \\
\hline
\end{tabular}

PAIN

There was no significant difference between the patients who did or did not have pain (Table 3).

\section{SIZE OF HAEMORRHOIDS SEEN ON} PROCTOSCOPY

There was no significant difference between those that appeared large and those that appeared small (Table 4).

TIGHTNESS OF ANAL CANAL ON DILATATION In 41 patients who were treated by dilatation, a note was made of the ease with which the anal canal could be stretched under anaesthesia. The mean maximum resting anal pressure of those who felt tight $(115.0 \pm$ $18.6 \mathrm{SD} \mathrm{cm} \mathrm{H}_{2} \mathrm{O}, \mathrm{n}=31$ ) was significantly higher than those who did not feel so tight $(99.8 \pm 23.6 \mathrm{SD}$ $\left.\mathrm{cm} \mathrm{H}_{2} \mathrm{O}, \mathrm{n}=10, \mathrm{P}<0.05\right)$.

\section{BOWEL HABIT}

Bowel frequency

Thirty-one per cent of the patients with haemorrhoids had a bowel frequency of less than once a day, compared with $15 \%$ of the controls (Table 5). This difference was not significant $\left(\chi^{2}=3 \cdot 74, \mathrm{P}<0.05\right)$.

\section{Straining at stool}

Straining at stool was more common in patients with haemorrhoids $(57 \%)$ than in the controls $(20 \%)$ (Table 6). This difference was significant $\left(\chi^{2}=13.7\right.$ $P<0.001)$. Of the patients with haemorrhoids, $41 \%$ had a history of straining before symptoms started. 
Table 3 Pain

\begin{tabular}{|c|c|c|c|}
\hline & $\begin{array}{l}\text { Mean max. RAP } \\
\mathrm{cm} \mathrm{H}_{2} \mathrm{O}\end{array}$ & $S D$ & $n$ \\
\hline $\begin{array}{l}\text { No pain } \\
\text { Pain sometimes } \\
\text { Pain often }\end{array}$ & $\begin{array}{l}105 \cdot 4 \\
111 \cdot 4 \\
110.9\end{array}$ & $\begin{array}{l}22 \cdot 6 \\
19 \cdot 7 \\
25 \cdot 6\end{array}$ & $\begin{array}{l}48 \\
12 \\
24\end{array}$ \\
\hline
\end{tabular}

Table 4 Size of haemorrhoids seen on prostoscopy

\begin{tabular}{llll}
\hline & $\begin{array}{l}\text { Mean max. RAP } \\
c m H_{3} O\end{array}$ & $S D$ & $n$ \\
\hline Small & 101.6 & 24.7 & 14 \\
Medium & 112.7 & 27.6 & 24 \\
Large & 106.0 & 19.3 & 43 \\
\hline
\end{tabular}

Table 5 Bowel frequency

\begin{tabular}{lcccc}
\hline Bowel frequency & \multicolumn{3}{c}{ Haemorrhoids } & \multicolumn{2}{c}{ Controls } \\
\hline & & $(\%)$ & & $(\%)$ \\
Less than once per day & 26 & $30 \cdot 9$ & 6 & $15 \cdot 0$ \\
Once per day & 44 & $52 \cdot 4$ & 27 & $67 \cdot 5$ \\
More than once & 14 & $16 \cdot 7$ & 7 & $17 \cdot 5$ \\
Total & 84 & 100 & 40 & 100 \\
\hline
\end{tabular}

Table 6 Straining at stool

\begin{tabular}{|c|c|c|c|c|c|c|}
\hline & \multirow{2}{*}{\multicolumn{2}{|c|}{ Controls }} & \multicolumn{4}{|c|}{ Haemorrhoids } \\
\hline & & & \multicolumn{2}{|c|}{$\begin{array}{l}\text { Before symptoms } \\
\text { started }\end{array}$} & \multicolumn{2}{|c|}{$\begin{array}{l}\text { After symptoms } \\
\text { started }\end{array}$} \\
\hline $\begin{array}{l}\text { Never } \\
\text { Sometimes } \\
\text { Often } \\
\text { Total }\end{array}$ & $\begin{array}{r}32 \\
8 \\
0 \\
40\end{array}$ & $\begin{array}{r}(\%) \\
80 \\
20 \\
0 \\
100\end{array}$ & $\begin{array}{l}48 \\
22 \\
12 \\
82\end{array}$ & $\begin{array}{c}(\%) \\
58.6 \\
26.8 \\
14.6 \\
100\end{array}$ & $\begin{array}{l}36 \\
29 \\
19 \\
84\end{array}$ & $\begin{array}{c}(\%) \\
42 \cdot 9 \\
34 \cdot 5 \\
22 \cdot 6 \\
100\end{array}$ \\
\hline
\end{tabular}

Table 7 Straining at stool and predominant symptom

\begin{tabular}{lrccc}
\hline & \multicolumn{4}{c}{ History of straining } \\
\cline { 2 - 5 } & Never & Sometimes & Often & Total \\
\hline Bleeding only & 10 & 6 & 2 & 18 \\
Bleeding worse than prolapse & 9 & 3 & 1 & 13 \\
Both symptoms troublesome & 7 & 9 & 8 & 24 \\
Prolapse worse than bleeding & 5 & 9 & 5 & 19 \\
Prolapse only & 4 & 1 & 5 & 10 \\
Total & 35 & 28 & 21 & 84 \\
\hline
\end{tabular}

\section{Straining at stool and predominant symptom}

The predominant symptom was grouped in one of five ways, as shown in Table 7. The history of straining at stool in the Table refers to the presence or absence of this symptom at any time, either before or after the symptoms of haemorrhoids started. From this Table it appears that absence of straining is associated with bleeding. For statistical testing, the intermediate groups were left out with the following results: when bleeding was the main symptom 19 never strained, while three did so often; when prolapse was the main symptom nine never strained, while 10 frequently did so. This association was significant $\left(\chi^{2}=5.5\right.$ P $\left.<0.025\right)$. The maximal anal pressure in those patients who never strained $(108.5 \pm 21.3 \mathrm{SD}, \mathrm{n}=35)$ was no different from those who strained $(107 \cdot 5 \pm 24 \cdot 4 \mathrm{SD}, \mathrm{n}=49)$.

\section{ONSET OF SYMPTOMS IN PATIENTS WITH}

HAEMORRHOIDS

In $44(52 \%)$ bleeding was the first symptom and in 31 $(37 \%)$ prolapse came first. In nine $(11 \%)$ both symptoms appeared at about the same time.

Of the 44 who had had bleeding first, 26 subsequently developed some prolapse and of 31 who had had prolapse as their first symptom, 21 later developed some bleeding. The mean duration of symptoms in those who had had bleeding as the first symptom $(7 \cdot 3 \pm 7 \cdot 5$ SD years) was not very different from those who had prolapse as the first symptom $(10.5 \pm 9.0 \mathrm{SD}$ years $)$.

\section{PRESSURE AND MOTILITY AFTER}

TREATMENT BY DILATATION

There was a very significant reduction in pressure from $113.9 \pm 19.1 \mathrm{SD} \mathrm{cm} \mathrm{H}_{2} \mathrm{O}$ to $69.8 \pm 15.8 \mathrm{SD}$ $\mathrm{cm} \mathrm{H}_{2} \mathrm{O}$ in 46 patients measured one year after treatment of their haemorrhoids by dilatation.

Ultra slow waves were present before dilatation in 23 patients and one year later only one of these patients had a few low amplitude ultra slow waves.

Patients with ultra slow waves did much better than those without. Twenty-two of 23 patients with ultra slow waves preoperatively had complete relief of symptoms, while of 29 without ultra slow waves only 13 had a perfect result. Four patients in the latter group required a haemorrhoidectomy for uncontrolled prolapse.

\section{Discussion}

The results of this study suggest that the internal sphincter is overactive in some patients with haemorrhoids. The abnormality of the sphincter when present did not show any clear relationship with type or severity of the symptoms or with size or degree of haemorrhoids. Is this abnormality primary or secondary? Anal dilatation abolishes ultra slow waves and reduces high pressure. Is this how dilatation works?

The nature of haemorrhoids has been recently discussed (Thomson, 1975) with the conclusion that haemorrhoids are nothing more than a downward displacement of normal anal cushions. If the internal sphincter activity measured in some patients produces a degree of stenosis in the anal canal, this 
would lead to a high shearing force in the anal canal during a bowel action, with consequent displacement of normal structures. Correction of the stenosis by dilatation should stop the prolapse provided it has not progressed too far. This view is supported by the observation that the best results for the dilatation treatment were obtained in those with the most active internal sphincter as judged by the presence of high amplitude ultra slow waves.

If this is how dilatation works, the sphincter abnormality is presumably primary. There must be other factors leading to the development of symptoms because internal sphincter activity was normal in several patients.

Straining at stool has been suggested as a cause of haemorrhoids (Graham-Stewart, 1963). The present study confirmed that straining occurred more frequently than in controls, though $43 \%$ of patients denied any difficulty with bowel actions. Straining could be due to either hard stools or an unyielding sphincter. There was no difference in anal pressure between those who did strain and those who did not, so hard stools may be more important as a cause of straining. The observation that there was a significant association between bleeding and absence of straining and of prolapse with straining suggests that straining may be the factor which determines the predominant symptoms rather than being the cause of haemorrhoids.

Another factor in the development of haemorrhoids may be vascular distension of the anal cushions (the vascular hyperplasia theory, Stelzner, 1963). Clinical observation suggests that this may be so and one small study has demonstrated the arterial nature of blood in the anal cushions (Thulesius and Gjöres, 1972).

More studies of sphincter function, local blood flow, and bowel habits in relation to symptoms are required to elucidate the nature and cause of haemorrhoids.

I would like to thank all the consultants of the University Hospital of South Manchester who allowed me to examine many of their patients and Mr N. F. Kirkham and Professor R. A. Sellwood for their interest and advice. The recording facilities were kindly provided by Professor J. C. Brocklehurst. I am most grateful to Miss Linda Hunt who has supervised the statistical analysis and to $\mathrm{Mr} \mathrm{K}$. Smith for his help with the recordings. I also wish to thank Mrs B. Cusick for her nursing help and Mrs Jennifer Holmes for typing this paper.

\section{References}

Graham-Stewart, C. W. (1963). What causes haemorrhoids? Diseases of the Colon and Rectum, 6, 333-344.

Hancock, B. D., and Smith, K. (1975). The internal sphincter and Lord's procedure for haemorrhoids. British Journal of Surgery, 62, 833-836.

Kerremans, R. (1969). Morphological and Physiological Aspects of Anal Continence and Defaecation. Arscia Uitgäven: Brussels.

Stelzner, F. (1963). Haemorrhoids and other diseases of the corpus cavernosum recti and the anal canal. German Medical Monthly, 8, 177-182.

Thomson, W. H. F. (1975). The nature of haemorrhoids. British Journal of Surgery, 62, 542-552.

Thulesius, O., and Gjöres, J. E. (1973). Arterio-venous anastomoses in the anal region with reference to the pathogenesis and treatment of haemorrhoids. Acta Chirurgica Scandinavica, 139, 476-478. 